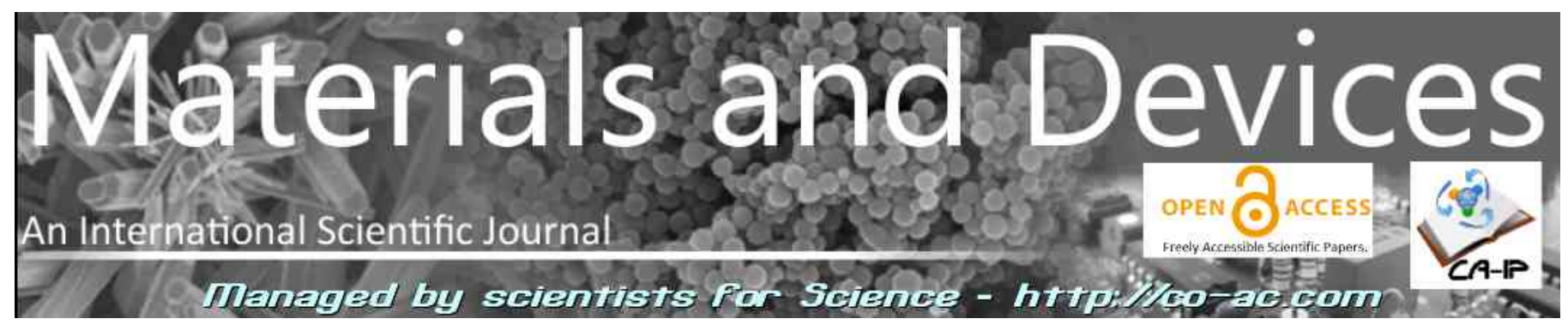

\title{
LEAD-FREE BNT PIEZOELECTRIC THIN FILMS BY SOL-GEL METHOD
}

\author{
S. Abou Dargham (1, 2), F. Ponchel (1), M. Soueidan (3), A. Khoury (2), \\ J. Assaad (1), D. Remiens (1), D. Zaouk (2)
}

(1) IEMN - DOAE, MIMM Team, University of Valenciennes, France

(2) Applied Physics Laboratory, Lebanese University, Lebanon

(3) Lebanese Atomic Energy Commission - CNRS, Riad I Solh, Lebanon

Corresponding author: Sara.AbouDargham@etu.univ-valenciennes.fr

RECEIVED: 21 september 2016 / RECEIVED IN FINAL FORM: 24 november 2016 / ACCEPTED: 30 november 2016

\begin{abstract}
The objective of this work is to synthesize lead-free piezoelectric thin films by the Sol-Gel method: bismuth sodium titanate $\left(\mathrm{Bi}_{0.5} \mathrm{Na}_{0.5} \mathrm{TiO}_{3}\right.$ or $\left.\mathrm{BNT}\right)$. BNT films were annealed with the rapid thermal process (RTP). The film treated at $700^{\circ} \mathrm{C}$ is dense and well crystallized in the perovskite phase. The first results of electrical characterizations showed promising dielectric, ferroelectric and piezoelectric performance. At $12 \mathrm{kHz}$, the dielectric constant and losses are 430 and 0.07 , respectively. Ferroelectric hysteresis measurements indicated a remanent polarization of $10 \mu \mathrm{C} / \mathrm{cm}^{2}$, associated with a coercive field of $70 \mathrm{kV} / \mathrm{cm}$. The piezoelectric properties of BNT films were studied with a laser Doppler interferometer: a piezoelectric coefficient ( $d_{33 \text { effmax }}$ ) of $42 \mathrm{pm} / \mathrm{V}$ was measured.
\end{abstract}

Keywords: PIEZOELECTRIC, LEAD-FREE, SOL-GEL, THIN FILMS, BNT.

\section{Introduction}

Lead zirconate titanate $\left(\mathrm{Pb}(\mathrm{Zr}, \mathrm{Ti}) \mathrm{O}_{3}\right.$ or $\left.\mathrm{PZT}\right)$ are widely used in the microelectronics industry due to their ferroelectric and piezoelectric properties [1]. However, the RoHS directive made by the European Union took effect on july 2006. This directive restricts the use of 6 hazardous substances ( $\mathrm{Pb}$, $\mathrm{Hg}, \mathrm{Cd} . .$.$) in electronic and electrical equipment [2].$ Therefore, lead-free piezoelectric materials have been attracting attention as new materials in place of PZT ${ }^{[3]}$.
Bismuth sodium titanate $\left(\mathrm{Bi}_{0.5} \mathrm{Na}_{0.5} \mathrm{TiO}_{3}\right.$ or $\left.\mathrm{BNT}\right)$ is a promising lead-free piezoelectric material. BNT ceramics have strong ferroelectric properties (remnant polarization $\mathrm{Pr}_{\mathrm{r}}=38 \mu \mathrm{C} / \mathrm{cm}^{2}$, Curie temperature $T_{c}=320^{\circ} \mathrm{C}$ and coercive field $E_{c}=73 \mathrm{kV} / \mathrm{cm}$ ) and relatively high piezoelectric properties $\left(\mathrm{d}_{33}=60-90 \mathrm{pm} / \mathrm{V}\right.$ ) ${ }^{[4]}$. BNT is a promising material for different applications (based on piezoelectric properties, pyroelectric and electrocaloric effects, etc.). In the present work, structural and electrical proprieties of BNT thin films prepared by the Sol-Gel method were studied. 


\section{Experimental details}

The objective of this work is to synthesize a lead-free piezoelectric material by the Sol-Gel method: the bismuth sodium titanate (BNT). Bismuth nitrate III penta-hydrate $\left[\mathrm{Bi}\left(\mathrm{NO}_{3}\right)_{3} .5 \mathrm{H}_{2} \mathrm{O}\right]$, sodium nitrate [NaNO3] and titanium (IV) isopropoxide $\left[\mathrm{Ti}\left(\mathrm{OCH}\left(\mathrm{CH}_{3}\right)_{2}\right)_{4}\right]$ were used to prepare the solution of BNT. Nitrates were dissolved in acetic acid and water at $70^{\circ} \mathrm{C}$. Then the mixture was introduced to a prepared solution of titanium isopropoxide in acetylacetone. After stirring at room temperature, a stable yellow sol precursor of BNT was obtained. The solution was deposited by spin coating (at a speed of $3000 \mathrm{rpm}$ for $20 \mathrm{~s}$ ) on a $\mathrm{Pt} / \mathrm{Ti} / \mathrm{SiO} 2 / \mathrm{Si}$ substrate. Then thermal processes (drying, pyrolysis and annealing) were applied; BNT films were annealed with the rapid thermal processor (RTP) after each layer deposition in order to reduce thermal stresses. LNO top electrodes were deposited on the films by magnetron sputtering and patterned by a photolithography liftoff process for the subsequent measurements. X-Ray Diffraction (XRD, Siemens D5000, Germany) and Scanning Electron Microscope (SEM, Zeiss Ultra 55) analyses were used to examine the crystalline structure and surface morphology of BNT films. Dielectric properties of BNT films were studied using an impedance analyzer (HP 4192A). For the polarization hysteresis ( $P-E$ ) loops, we have used an aixACCT TF 2000 analyzer to study the ferroelectric properties at the macroscopic scale of BNT films.

\section{Results and Discussions}

Figure 1 shows the XRD patterns of the BNT films annealed at different temperature by the RTP. At $700^{\circ} \mathrm{C}$, the BNT thin film is completely crystallized in the rhombohedral perovskite phase of $\mathrm{Bi}_{0.5} \mathrm{Na}_{0.5} \mathrm{TiO}_{3}$.

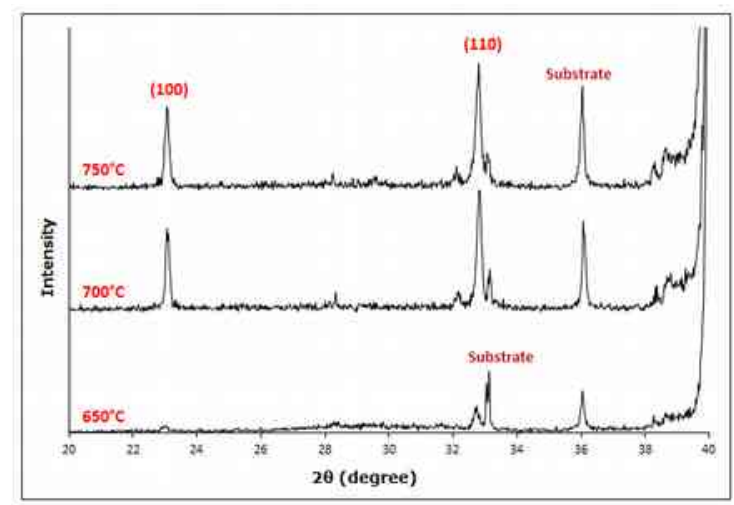

Figure 1: XRD patterns of BNT thin films.

Scanning electron microscopy (SEM) micrographs of BNT thin films annealed at $700^{\circ} \mathrm{C}$ and $750^{\circ} \mathrm{C}$ are shown in figure

2. BNT films annealed at $700^{\circ} \mathrm{C}$ present dense and uniform grains. However, in increasing the annealing temperature $\left(750^{\circ} \mathrm{C}\right)$ cracks and pores were produced. As it can be seen from the cross-sectional micrographs, the film annealed at $700^{\circ} \mathrm{C}$ has a uniform thickness (about $350 \mathrm{~nm}$ ). This film exhibits a relatively dense grained structure.
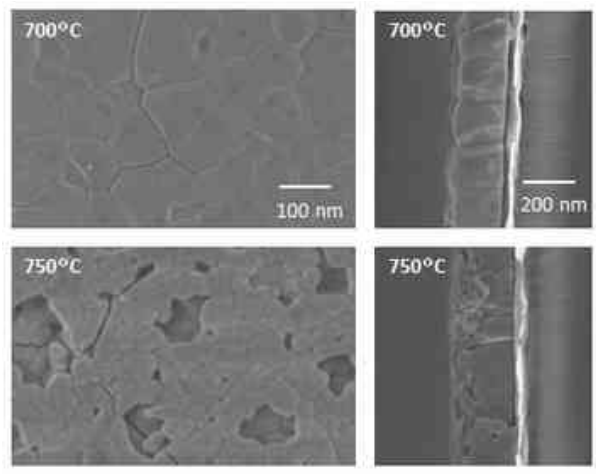

Figure 2: SEM micrographs of BNT thin films.

Figure 3 shows the dielectric permittivity and dielectric loss as a function of the applied electrical field for the BNT film annealed at $700^{\circ} \mathrm{C}$ measured at room temperature at $12 \mathrm{kHz}$. Dielectric constant and loss tangent loops appear approximately symmetric, with a typical hysteresis behavior for ferroelectric capacitors. The maximum dielectric permittivity and loss factor were about 430 and 0.07 , respectively.

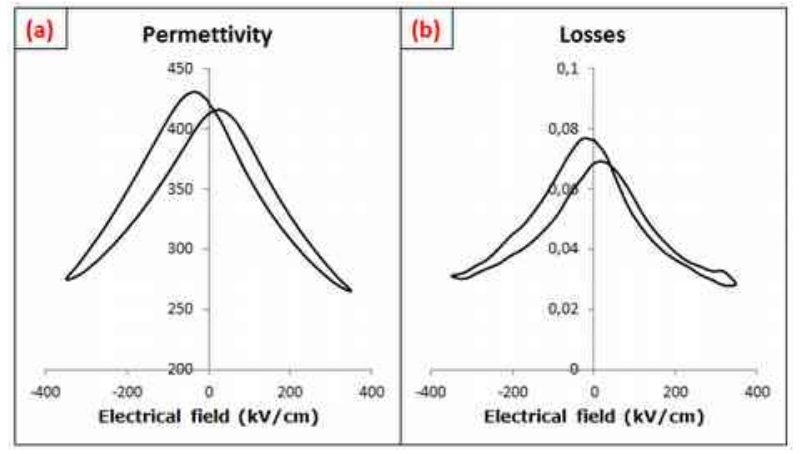

Figure 3: Electrical field dependences of (a) the permittivity and (b) the dielectric losses for the BNT thin film.

Figure 4 shows hysteresis loops of a $350 \mathrm{~nm}$-thick BNT film at room temperature. Remanent polarizations $\left(P_{r}\right)$ of $10 \mu \mathrm{C} / \mathrm{cm}^{2}$, associated with a coercive field $\left(E_{c}\right)$ of $70 \mathrm{kV} / \mathrm{cm}$, were measured for an applied electric field of $350 \mathrm{kV} / \mathrm{cm}$. Increasing the applied electric field (from $12 \mathrm{~V}$ to $16 \mathrm{~V}$ ) leads to non-symmetric loop due to the leakage currents and to the non-symmetry of the top and bottom electrodes (LNO - Pt) ${ }^{[5]}$.

The piezoelectric coefficient was measured using a modified Laser Doppler vibrometer. The measurement method as pro-

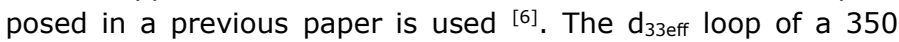
$\mathrm{nm}$ thick BNT film is represented in figure 5 . The maximum 
value of $d_{33}$ piezoelectric coefficient measured at $270 \mathrm{kV} / \mathrm{cm}$ is $42 \mathrm{pm} / \mathrm{V}$.

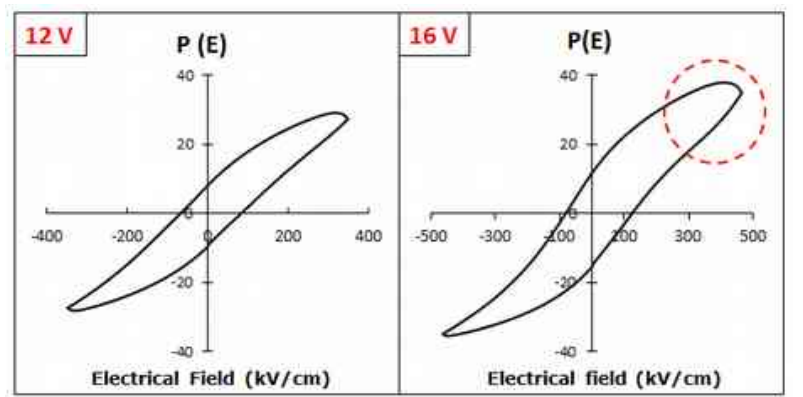

Figure 4: Room temperature macroscopic ferroelectric hysteresis (P-E) loops measured for a BNT film, for an applied voltage of 12 and $16 \mathrm{~V}$.

\section{Conclusion}

Polycrystalline piezoelectric lead-free thin films (BNT) were deposited on $\mathrm{Pt} / \mathrm{TiO} 2 / \mathrm{SiO} 2 / \mathrm{Si}$ substrates by an optimized Sol-Gel/Spin-coating process. The structural and morphological analyses showed that the films annealed at $700^{\circ} \mathrm{C}$ with the rapid thermal processor (RTP) is dense and well crystal- lized in the perovskite phase. The values of the permittivity and the losses are 430 and $7 \%$, respectively. The remanent polarization and coercive field values of BNT thin films are 10 $\mu \mathrm{C} / \mathrm{cm}^{2}$ and $70 \mathrm{kV} / \mathrm{cm}$ when the maximum applied electric field is $350 \mathrm{kV} / \mathrm{cm}$. First results of piezoelectric characterizations at the macroscopic level showed promising piezoelectric response $\left(\mathrm{d}_{33}=42 \mathrm{pm} / \mathrm{V}\right)$.

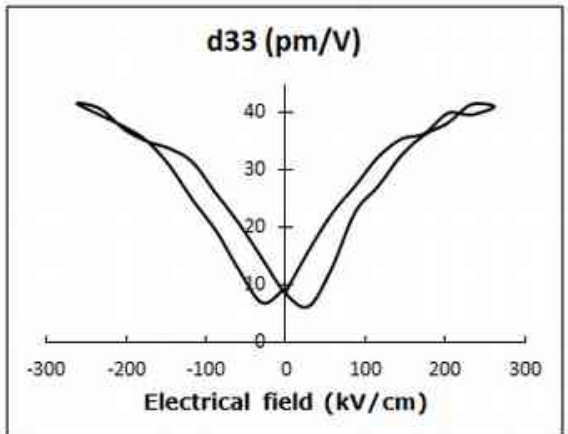

Figure 5: $d_{33 \text { eff }}(E)$ loop of BNT film.

\section{Acknowledgements:}

The authors acknowledge the financial support provided by the Lebanese National Council for Scientific Research (CNRS-L).

\section{REFERENCES}

1. T. Yamamoto, Japanese Journal of Applied Physics, vol 35, p 5104 (1996)

2. Official Journal of the European Union, vol 46, p 19 (2003)

3. T. Takenaka, H. Nagata, Y. Hiruma, Japanese Journal of Applied Physics, vol 47, p 3787 (2008)

4. A. Herabut, A. Safari, Journal of the American Ceramic Society, vol 80, p 2954 (1997)

5. Z Z Zhou, J Xue, W Li, J Wang, H Zhu, J Miao, Applied Physics Letter, vol.85, p 804 (2004)

6. R. Herdier, D. Jenkins, E. Dogheche, D. Remiens, M. Sulc, Review of Scientific Instruments, vol. 77, (2006) 